\title{
Os cursos de engenharia no Brasil e as transformações nos processos produtivos: do século XIX aos primórdios do século XXI
}

Sara Rios Bambirra Santos

Psicóloga, pós-graduada em Gestão e Tecnologia da Qualidade. Mestranda em Educação Tecnologica pelo Centro Federal de Educação Tecnológica de Minas Gerais (CEFET-MG).

sarabambirra@yahoo.com.br

Maria Aparecida da Silva

Mestre em Planejamento Educacional pela Pontifícia Universidade Católica do Rio de Janeiro (PUC/RJ); doutora em Educação pela Universidade Estadual de Campinas (UNICAMP). Professora do Mestrado em Educação Tecnológica no Centro Federal de Educação Tecnológica de Minas Gerais (CEFET-MG)

masilva46@oi.com.br

\section{Resumo}

Este artigo trata das relações entre as transformações nos processos produtivos e o ensino de engenharia no Brasil nos séculos XIX, XX e início do XXI. Supõese haver uma estreita relação entre essas transformações e as modificações no ensino de engenharia. A revisão bibliográfica subsidia o desenvolvimento do presente artigo. Na primeira parte, apresenta-se a história dos cursos de engenharia no Brasil nos seus primórdios e durante o século XIX. A segunda parte focaliza as transformações nos cursos de engenharia do século $X X$ e início do XXI.

Palavras-chave: curso de engenharia; processos produtivos; abordagem histórica. 


\section{O ensino de engenharia no Brasil - seus primórdios e durante o século XIX}

O início da história do ensino de engenharia no Brasil, de acordo com Bazzo e Pereira (1997), ocorreu de forma periódica. A referência mais antiga ao ensino de engenharia no Brasil data de 1648-1650, quando o holandês Miguel Timermans foi contratado para ensinar sua "arte e ciência" (TELLES, 1994). $O$ início do ensino formal de Engenharia no país, porém, foi com a Academia Real Militar, criada em 4 de dezembro de 1810 pelo príncipe regente (futuro rei Dom João VI), substituindo a Real Academia de Artilharia, Fortificação e Desenho instalada em 17 de dezembro de 1792. A Academia Real Militar foi a primeira escola a funcionar nas Américas e a terceira no mundo, sendo antecedida somente pela Escola de Pontes e Calçadas, em I747, na França e pela Academia Real de Fortificação, Artilharia e Desenho, em Portugal, em 1790 (UNIVERSIA, 2008). ' Antes da abertura da Academia Real Militar, havia cursos regulares de engenharia no Brasil no formato de aulas isoladas. Em 1699 foi criada a Aula de Fortificação no Rio de Janeiro e em 1710, a Aula de Fortificação e Artilharia em Salvador (TELLES, 1994). Assim, a Academia Real Militar responsabilizava-se pelo ensino das ciências exatas e engenharia em geral. Formava não só "oficiais para as armas", mas também "engenheiros geógrafos e topógrafos com a finalidade de conduzir estudos e elaborar trabalhos em minas, caminhos, portos, canais, pontes, fontes e calçadas" (INSTITUTO MILITAR DE ENGENHARIA, I999, p. 3). Naquela época, de acordo com Kawamura ( I 98I), a formação e o trabalho estavam estritamente ligados à "arte militar", e a tecnologia interessava apenas enquanto meio de segurança e repressão. Ao longo dos anos, a Academia Real Militar passou por reformas e transformações. De acordo com o Instituto Militar de Engenharia (1999) e com Bazzo e Pereira (1997), seu nome mudou quatro vezes: Imperial Academia Militar ( I822), Academia Militar da Corte (I832), Escola Militar (I840) e Escola Central (I859).

De acordo com Weiss (1969), no início do século XIX a base da economia brasileira era a agricultura, representada pelos plantios de cana-de-açúcar na primeira metade do século e do café na segunda metade. Em 1808 iniciaramse atividades industriais no Brasil com o predomínio das fábricas de algodão.

\footnotetext{
' Entretanto, os documentos pesquisados se contradizem em relação ao nome da primeira escola de engenharia portuguesa. Há fontes que afirmam que a primeira escola portuguesa se denominava "Escola de Pontes e Calçadas", como a francesa. Porém, outras fontes afirmam que a primeira instituição de ensino destinada à engenharia era a Academia Real de Fortificação, Artilharia e Desenho, nome similar à escola brasileira.
} 
Em 7 de setembro de 1822, com a proclamação da independência, o Brasil se liberta de Portugal, mas economicamente nada muda. Por sua vez, durante 0 Segundo Reinado, entre 1840 e I889, intensificam-se as primeiras manufaturas e fábricas no Brasil. A pequena indústria brasileira, porém, não era páreo para a livre concorrência estrangeira: os produtos chegavam da Europa, principalmente da Inglaterra, com qualidade e preços que superavam a mercadoria produzida no Brasil. Essa situação se agravou ao longo dos anos: enquanto o desenvolvimento industrial europeu era contínuo, os métodos brasileiros estavam restritos a padrões ultrapassados. Ainda assim, mesmo diante da concorrência europeia, as indústrias de manufatura, tecidos e metalurgia conseguiram se estabelecer no país (PRADO JUNIOR, 1980).

No decorrer do Segundo Reinado, de acordo com Weiss (1969), houve também o desenvolvimento do comércio e das obras públicas. Em $I^{\circ}$ de março de 1858, o ministro de Guerra, Jerônimo Coelho, assina o decreto n 2 . I I6, criando a Escola Central do Exército no Brasil, que se encarrega do curso de Engenharia Civil, até então inexistente no país. Com estas modificações, o ensino militar ficou a cargo da Escola de Aplicação do Exército, então denominada Escola Militar e de Aplicação de Exército, e da Escola Militar do Rio Grande do Sul (BRASIL, 1973). O decreto imperial n 5.600, de 25 de abril de I874, transformou a Escola Central em Escola Politécnica do Rio de Janeiro, voltada exclusivamente para o ensino das Engenharias e subordinadas a um ministro civil. Assim o ensino de engenharia desvincula-se de sua origem militar (SILVA, 2002; TELLES, 1994). No entanto, antes desse decreto havia outras duas instituições dedicadas ao ensino de engenharia. A lei provincial $n^{\circ} 10$, de março de 1835, criou o Gabinete Topográfico para formar topógrafos, engenheiros de estradas e medidores de terras. Outra escola foi o Imperial Instituto de Agronomia, localizado na Bahia, com o objetivo de formar engenheiros agrônomos e regentes rurais (TELLES, 1994).

Entretanto, de acordo com Prado Junior (1980), na segunda metade do século XIX a economia agrícola se transformou. Com a decadência das lavouras tradicionais - cana-de-açúcar, algodão e tabaco - desenvolveu-se a agricultura cafeeira. A partir de 1860, a exportação do café começou a aumentar em proporções crescentes e o Brasil chegou a ser o grande produtor mundial, com quase monopólio do comércio internacional. Nesse sentido, a crescente produção cafeeira pressionou a mecanização das indústrias rurais, a instalação de algumas primeiras manufaturas e a construção de estradas de ferro. 
A partir de 1880, no Segundo Império, houve acentuado progresso industrial. Fundaram-se 150 indústrias, das quais $60 \%$ eram destinadas ao setor têxtil, $15 \%$ à alimentação, $10 \%$ à indústria de produtos químicos e similares, $3,5 \%$ à de vestuários e objetos de toucador e 3\% à metalurgia (WEISS, 1969b). O ensino de engenharia também passa a crescer. Em I 2 de outubro de 1876 , criou-se a Escola de Minas de Ouro Preto. Ainda no século XIX, outras cinco escolas de engenharia foram implantadas: a Politécnica de São Paulo, em I893; a Politécnica do Mackenzie College e a Escola de Engenharia do Recife, em I896; a Politécnica da Bahia e a Escola de Engenharia de Porto Alegre, em I 897 (BAZZO, PEREIRA, I997; TELLES, 1993). De acordo com Kawamura ( 1981 ), do final do Império até 1930, a base econômica da época era agroexportadora (cafeeira). Portanto, a missão da escola superior era a de formar profissionais aptos a trabalharem na estrutura burocrática e política que a agricultura exigia, ou exercerem profissões liberais como advocacia, medicina e engenharia. Laudares afirma que:

as oportunidades de trabalho para os engenheiros pautavam-se assim pela expansão dos setores ferroviários, hidrelétricos, edificações e de serviços públicos, correntes da produção agroexportadora. Sua participação social era restrita se comparada com a do advogado e a do médico (LAUDARES, 1992, p.25).

Contudo, o interesse de outras nações na agroindústria brasileira fez com que as primeiras Escolas de Engenharia fossem influenciadas e patrocinadas pelo capital estrangeiro (BAZZO, PEREIRA, LINSINGEN, 2000; CUNHA, 1999). A Escola de Minas de Ouro Preto, por exemplo, sofreu grande influência da École Polytechnique de Paris, mesmo sendo introduzida pelos portugueses. Enquanto a Escola de Engenharia do Mackenzie College foi construída através do capital norte-americano. $O$ ensino nas escolas de engenharia da época, até então, possuíam forte tendência pragmática, ou seja, consideravase válido o conhecimento baseado na experiência, desviando-se da abstração. Essa tendência, porém, conflitava com as condições estruturais do país, de perfil agroexportador: não havia ainda engenheiros altamente especializados, principalmente em tecnologia industrial (LAUDARES, 1992; CUNHA, 1999). No final do século XIX, o movimento filosófico positivista influenciaria as elites brasileiras, expressando-se na demanda pelas Escolas de Engenharia no Brasil, mas valorizando o ensino enciclopédico (CUNHA, I999; BAZZO, PEREIRA, LINSINGEN, 2000). Desse modo, as novas condições de ensino possibilitaram 
aos engenheiros formados atuarem em todos os campos da engenharia, pois forneciam uma "sólida formação básica que os habilitavam ao autodidatismo para as mudanças requeridas” (INSTITUTO MILITAR DE ENGENHARIA, I999, p.3).

\section{O ensino de engenharia no Brasil - século XX e início do XXI}

No final do século XIX e início do XX, o Brasil viveu uma grande crise no mercado econômico (WEISS, 1969a). O governo abordou várias tentativas de superá-la, porém não obtém êxitos duradouros para estabilizar seu mercado. Não obstante, após 1910, estourou no Brasil a crise da borracha, e o produto começou a ser excluído dos mercados internacionais pela concorrência do Oriente. Em seguida, mas em menor escala, a produção do cacau passou por situação semelhante (PRADO JUNIOR, I980). O mercado cafeeiro sofreu várias intervenções governamentais, já que era o principal produto comercial brasileiro. Em outubro de 1929, ocorreu o desfecho de mais uma tentativa de intervenção oficial no mercado do café. Além da falta de sucesso da tentativa brasileira, a crise se agravou devido ao crash da bolsa de Nova lorque (WEISS, 1969b).

Mesmo em meio a crises, desde 1880 , a indústria continuava ocupando cada vez mais espaço dentro da economia brasileira. Durante a Primeira Guerra Mundial, entre 1914 a 1918, a indústria brasileira obteve grande impulso, pois houve uma brusca diminuição da importação de manufatura dos países beligerantes e uma forte queda no câmbio, fator que contribui para a redução da concorrência estrangeira (PRADO JUNIOR, 1980). Naquele momento, formou-se no Brasil uma nova indústria, que começava a tomar conta do mercado: a carne congelada (setor frigorífico). Aproveitando-se de matéria-prima abundante, a indústria frigorífica passou a exportar para a Europa em detrimento do mercado interno. A indústria, a partir desse contexto, passou a ocupar um lugar de destaque na economia do país. No entanto, a situação industrial ainda era precária, pois havia carência de capital e investimentos sólidos na indústria brasileira, já que a aplicação financeira estatal era vista como muito mais certa e segura do que o investimento industrial.

Surge uma nova conjuntura econômica brasileira, mudanças econômicas, ideológicas e políticas do país e do mundo. Nesse contexto, as escolas de engenharia se voltam para a produção industrial. $O$ ensino seguia uma vertente pragmática, em que se focalizava o aspecto prático em detrimento do estilo enciclopédico. A eliminação do cunho teórico-genérico e a especialização vincularam- 
se aos interesses da produção industrial. A ideologia pragmática contribuía para a expansão das ideias de organização racional do trabalho, visando ao aumento da mais-valia (CUNHA, 1999; KAMAWURA, 198I). Nessa fase, estruturou-se um modelo de ensino brasileiro com maior ênfase à especialização do engenheiro sem, no entanto, perder as características de formação geral. A engenharia estruturada sobre a concepção pragmática proclamava o princípio do domínio do homem sobre a natureza para o benefício do próprio homem. Na prática, entretanto, de acordo com Cunha ( 1999), o princípio de dominação ultrapassou a relação com a natureza, estendendo-se a dominação do homem sobre o homem.

Assim, após a Primeira Guerra Mundial, grandes empresas estrangeiras montaram indústrias subsidiárias no Brasil, buscando contornar as pesadas tarifas alfandegárias, aproveitar-se da mão-de-obra barata ou privilegiar o Brasil devido à facilidade de transporte de mercadorias. Os ramos principais da sua produção eram veículos motores, produtos farmacêuticos e químicos, bem como aparelhos elétricos e alimentos. Finalmente, a siderurgia passa a receber crescentes investimentos estrangeiros, indústria até então pouco desenvolvida no Brasil devido à localização da matéria-prima (PRADO 26 JUNIOR, 1980). De acordo com Crivellari (2000), a partir da década de 1930, a concepção da engenharia se constituiu enquanto "ciência aplicada aos problemas concretos”, visando sua solução. As mudanças progressivas no ensino de engenharia resultaram "na maior divisão do trabalho do engenheiro e no crescente surgimento das novas especialidades, rompendo com a visão mítica do engenheiro-expert universal" (LAUDARES, RIBEIRO, 2000, p.493). O caráter elitista e seletivo do ensino de engenharia evidenciava as funções sociais da escola na reprodução da estrutura de classes e relações sociais de produção. Ao mesmo tempo em que a escola fornecia ao sistema social uma elite certificada tecnicamente, criava um "exército de reserva", direcionado para as funções menos qualificadas, porém essenciais ao regime capitalista. Ao selecionar os que constituirão a elite profissional, ela exercia sua função delegada de autoridade sobre determinada área de conhecimento técnico e de direito; função reforçada pela regulamentação profissional do engenheiro, na medida em que possibilitava sua seleção pelo próprio mercado de trabalho (KAMAWURA, 198I). Essa regulamentação em caráter nacional da profissão de engenheiro, arquiteto e agrimensor só ocorreu em 1933, por meio do decreto federal $n^{\circ} 23.569$, segundo Telles (1984). 
Até 1946, de acordo com Bazzo e Pereira (1997), existiam quinze instituições de ensino de engenharia. Kawamura (198I) ainda afirma que houve uma ampliação das escolas de engenharia no Brasil após a Segunda Guerra Mundial, principalmente a partir de 1955, já que as mudanças ocorridas no aparelho econômico propiciaram a utilização intensiva da tecnologia.

A política desenvolvimentista adotada pelo governo J.K. incentivou os investimentos no setor industrial e provocou um crescimento acelerado da indústria brasileira. Entre os anos de 1955 a 196I, o crescimento industrial do Brasil alcançou $80 \%$; a indústria de aço, $100 \%$, a mecânica, $125 \%$, as do setor elétrico e de comunicações, $380 \%$; a de equipamentos de transporte, $600 \%$. Entre 1950 a 1960, quase trinta e duas mil indústrias foram instaladas no país (eram 78.434 em 1950 e II 0.339 em 1960) (BRAICK, 2007, p.I2).

Com o apoio dos Estados Unidos, o Governo JK tinha um plano de desenvolvimento de metas para o Brasil (GORENDER; RAMPINELLI, 2002). Portanto, houve grande influência norte-americana no sistema educacional e econômico brasileiro com o objetivo de implantar novas universidades e remodelar as já existentes, no sentido de incrementar a educação técnica em prejuízo à formação humanística (KAWAMURA, 198I). Por conseguinte, para atender as demandas da indústria - em especial a automobilística - em meados da década de 1960, iniciou-se o curso de Engenharia de Operação, de curta duração, ministrado em três anos. Devido a essa duração, o curso competia com os cursos de bacharelado em Engenharia, ainda que fosse caracterizado como curso técnico de nível superior. Oferecia uma formação intermediária entre o técnico de nível médio e o engenheiro. Contudo, o curso Engenharia de Operações, no Brasil, teve curta duração: pouco mais de dez anos, já que o corporativismo dos engenheiros reagiu à denominação dessa nova classe de profissionais, "alegando que a denominação geraria confusões e propiciaria abusos, em detrimento da qualidade dos serviços prestados" (BRASIL, 2007, p. 3).

O trabalho de desenvolvimento da engenharia brasileira prossegue atrelado ao desenvolvimento do país. A década de 1970 significou um período de grande expansão industrial para o Brasil: marcado pelo crescimento da produção, do emprego industrial e pelo desenvolvimento na estrutura de gestão da força de trabalho. Contudo, esse período foi descrito por Fleury (1983) como um período de "rotinização". Abramo (1999) e Carvalho (1987) denunciaram suas "formas predatórias de uso da força de trabalho". O gerenciamento do trabalho fundamentou-se na fragmentação das tarefas, no emprego de profis- 
sionais não-qualificados, na alta taxa de rotatividade e, principalmente, no controle dos trabalhadores. Essas características ainda se apoiavam na legislação trabalhista, baseadas no contrato individual de trabalho e no contexto político autoritário que predominava no país.

Ainda assim o sistema de trabalho fordista no Brasil entra em crise na década de 1980, exigindo mudanças nas formas de produção e gestão (ABREU NETO, 2005). Essas mudanças, ocorridas dentro do contexto industrial, "afetaram a base constitutiva de formação profissional em geral e, em particular, a dos engenheiros" (LAUDARES; RIBEIRO, 2000, p.493). Até então, a orientação filosófica e curricular dos cursos de engenharia, de acordo com Cunha (1999), tiveram por base a razão instrumental. A ênfase do curso se voltava gradativamente para atender ao desenvolvimento e à produção industrial, enquanto suas atividades eram direcionadas estrategicamente para promover a adaptação do estudante ao sistema produtivo.

No início da década de 1990, durante o governo de Collor de Melo, o cenário brasileiro enfrentou um quadro de instabilidade econômica, criado justamente pela maior abertura da economia brasileira e concorrência estrangeira. Várias empresas passaram a aplicar modelos de modernização centrados em ganhos de produtividade, no envolvimento dos trabalhadores e na inter-relação com outras empresas. Como consequência desse cenário econômico-social e político, a educação também transforma-se. As entidades empresariais começaram a demandar um novo perfil de "qualificação da força de trabalho conforme as novas necessidades postas pelos processos de produção e organização do trabaIho, típicos das unidades industriais de ponta" (ANDRADE, 2002, p.2). Para atender essa necessidade empresarial, criou-se o Programa Brasileiro da Qualidade e Produtividade (PBQP) e o Programa de Apoio à Capacitação Tecnológica da Indústria (PACTI) com o objetivo de adequar as condições de produção do país aos níveis de competitividade internacionais. Um dos subprogramas do PBQP era responsável pela formulação da política educacional do novo governo, que teria como eixo a noção de "educação para a competitividade".

Finalmente, em 1990, implantou-se o processo de reformulação curricular. O curso de Engenharia passa a ter como objetivo a formação de profissionais mais críticos. De acordo com Cunha (1999), o final do século XX é marcado pela coexistência de duas abordagens curriculares dentro dos cursos de engenharia: do saber técnico-instrumental e do saber emancipatório. Portanto, era responsabilidade do professor utilizar a sua liberdade em sala de aula para 
atuar de forma transformadora. Consequentemente, as duas abordagens curriculares compunham uma trajetória única e cooperativa no desenvolvimento do currículo do curso de engenharia.

Nos últimos anos, o movimento de reestruturação produtiva impõe novas necessidades no âmbito do setor industrial brasileiro, principalmente no que se refere ao perfil da força de trabalho. Demanda-se um profissional que se adéque às características globalizadas da gestão e da tecnologia, com uma formação de caráter generalista, porém que possua igualmente conhecimentos específicos relativos ao trabalho que desenvolve. Essas demandas empresariais serviram e servem de orientação para os "princípios norteadores da prática pedagógica escolar em âmbito nacional” (ANDRADE, 2002, p.I I). Para atender a demanda dos processos produtivos em transformação acelerada, os engenheiros começam a atuar em novas áreas. Hoje há aproximadamente $6 \mathrm{I}$ áreas de atuação profissional, de acordo com a resolução $n^{\circ} 1.010$ de 22 de agosto de 2005, que entrou em vigor no dia $1^{\circ}$ de julho de 2007. Para formar profissionais para atuar em novos setores, novos cursos de engenharia são criados. Com isso, constatou-se a aceleração de abertura de novos cursos de engenharia no período de 1980 até 2003. Na década de 1980 foram criados 22 cursos, nas décadas de 1990 e 1994, e entre 2000 e 2003, outros 77. Ou seja: na década de 1990, o Ministério da Educação e Cultura (MEC) autorizou o funcionamento de, em média, 9,4 novos cursos de engenharia por ano. Entre 2000 e 2003, foram inaugurados 19,25 novos cursos anualmente. Os cursos de engenharia, até hoje, surgem de acordo com a demanda do mercado. Atualmente há 44 modalidades ${ }^{2}$ de cursos, de acordo com dados do Instituto Nacional de Ensino e Pesquisa (INEP) (2005).

\section{Conclusão}

Percebe-se uma estreita relação entre as transformações nos processos

\footnotetext{
${ }^{2}$ Engenharia Geológica, Engenharia de Agrimensura, Engenharia Cartográfica, Engenharia Civil, Engenharia de Construção, Engenharia de Recursos Hídricos e Engenharia Sanitária, Engenharia Elétrica, Engenharia Industrial Elétrica, Engenharia Eletrotécnica, Engenharia de Computação, Engenharia de Comunicações, Engenharia de Redes de Comunicação, Engenharia Eletrônica, Engenharia Mecatrônica, Engenharia de Controle e Automação, Engenharia de Telecomunicações, Engenharia Industrial Mecânica, Engenharia Mecânica, Engenharia Aeroespacial, Engenharia Aeronáutica, Engenharia Automotiva, Engenharia Naval, Engenharia Industrial Química, Engenharia Química, Engenharia Bioquímica, Engenharia de Biotecnologia, Engenharia de Alimentos, Engenharia Têxtil, Engenharia de Materiais sem ênfase, Engenharia de Materiais com ênfase em Materiais Metálicos, Engenharia de Materiais com ênfase em Materiais Cerâmicos, Engenharia de Materiais Cerâmica, Engenharia de Materiais com ênfase em Materiais Poliméricos, Engenharia de Materiais Plásticos, Engenharia Metalúrgica, Engenharia de Fundição, Engenharia Física, Engenharia de Produção, Engenharia de Produção Civil, Engenharia de Produção de Materiais, Engenharia de Produção Elétrica, Engenharia de Produção Mecânica, Engenharia de Produção Química, Engenharia de Produção Têxtil, Engenharia Ambiental, Engenharia de Minas, Engenharia de Petróleo, Engenharia Industrial Madeireira, Engenharia Agrícola, Engenharia Florestal, Engenharia de Pesca.
} 
produtivos e as modificações no ensino de engenharia ao longo da história brasileira. $O$ ensino de engenharia no Brasil foi inaugurado com o objetivo militar - a fortificação de defesas -, isto é, servia aos interesses de Portugal para defender sua colônia da possível invasão de outros colonizadores no início do mercantilismo. Contudo, a base da economia brasileira, durante o século XIX, era a agricultura. Portanto, o ensino de engenharia, até então restrito a uma formação pragmática, voltou-se para um ensino enciclopédico e mais abrangente, o que possibilitou ao engenheiro atuar em áreas diversas. Igualmente, durante quase todo o século XIX, os investimentos econômicos e educacionais brasileiros visavam os interesses de Portugal. Assim, por motivos políticos e econômicos, o ensino de engenharia se desenvolveu em função dos interesses da metrópole. Já a partir da década de 1880 , o acentuado progresso industrial do Brasil passou a influenciar o ensino de engenharia: novos cursos foram criados, inauguraram-se novas escolas e cursos.

O século $X X$ inicia num contexto de turbulência econômica, em consequência da grande crise no mercado cafeeiro. No entanto, mesmo em meio a crises, o setor industrial cresce nesse início de século. $O$ ensino de engenharia se transforma, portanto, para atender às demandas do processo econômico. Já no Pós-Guerra, em 1945, o crescimento industrial estava principalmente atrelado a programas desenvolvimentistas: nesse mesmo período, também, constatou-se a ampliação das escolas de engenharia, que supriam as demandas da indústria brasileira. Durante a década de 1960, o mercado industrial continuou promissor: criou-se o curso de engenharia de operação, com duração de três anos, para atender o setor automobilístico. Finalmente, a partir de 1970, o Brasil se encontra num período de grande expansão industrial. Novos métodos e técnicas de produção são introduzidos nas indústrias, e essas mudanças, em curso até hoje, demandam um novo tipo de profissional, incluindo o engenheiro - busca que prossegue até a presente data. 


\section{Referências}

ABREU NETO, F. A. de. Princípios filosóficos constitutivos das tecnologias fordista e toyotista. Tese (Doutorado em Filosofia, Tecnologia e Sociedade) Universidade Complutense de Madri, Madri, 2005.

ABRAMO, L. O resgate de dignidade: greve metalúrgica e subjetividade operária. São Paulo: Unicamp e Imprensa Oficial, 1999.

ACADEMIA MILITAR. Resenha histórica. Disponível em: < http://www. academiamilitar.pt/index.php? $\mathrm{t}=4 \& \mathrm{tp}=\mid 40>$. Acesso: 18 fev. 2008.

ALVES, F. M. A guerra da restauração (1640-1668) no teatro de operações transmontano. Revista Militar. I 4 dez. 2005. Disponível em: <http://www. revistamilitar.pt /modules/articles/article.php?id=20 >. Acesso em: 19 fev. 2008.

ANDRADE, F. A. Reestruturação produtiva, estado e educação no Brasil de hoje. Revista Brasileira de Educação. Disponível em: < http:// www.anped.org.br/ reunioes/24/T09029079922 I3.DOC>. Acesso em: 20 set. 2007.

BAZZO, W. A.; PEREIRA, L. T. do V. Introdução à engenharia. 5. ed. Florianópolis: Universidade Federal de Santa Catarina - UFSC -, 1997.

BAZZO, W. A.; PEREIRA, L. T. do V.; LINSINGEN, I. von. Educação tecnológica: enfoques para o ensino de engenharia. Florianópolis: Universidade Federal de Santa Catarina - UFSC -, 2000.

BRAICK, P. A política nacional-desenvolvimentista. In: Casa da História. Populismo. 2007. Disponível em: <http://www.casadehistoria.com.br/ cont_31-09.htm>. Acesso em: 19 fev 2008.

BRASIL. Ministério da Defesa. Exército Brasileiro. Secretaria-Geral do Exército. Centro de Documentação do Exército. Brigadeiro Jerônimo Coelho (Contribuição ao bicentenário de seu nascimento). 1973. Disponível em: $<w w w . c d o c e x . e b . m i l . b r /$ arquivosDocs/Brig_Jeronimo_Coelho.doc>. Acesso em: 12 jul. 2007. 
BRASIL. Ministério da Educação. Conselho Nacional de Educação. Diretrizes Curriculares Nacionais Gerais para a Educação Profissional de Nível Tecnológico. Diário Oficial da União. Brasília, DF, 03 dez. 2002. Disponível em: <http:// http://portal.mec.gov.br/setec/arquivos/pdf/ parecer_cne29.pdf>. Acesso em: 02 jul.2007.

CARVALHO, R. Q. Tecnologia e trabalho industrial. Porto Alegre: L\&PM Editores, 1987.

\section{CONSELHO FEDERAL DE ENGENHARIA, ARQUITETURA E} AGRONOMIA. Resolução n I.010, de 22 de agosto de 2005. Diário Oficial da União. Brasília, DF, 30 ago. 2005. Disponível em: < http:// www.confea.org.br/>. Acesso em: 29 jul. 2007.

CRIVELLARI, H. Relação educativa e formação de engenheiros em Minas Gerais. In: BRUNO, L. B.; LAUDARES, J. B. (org.). Trabalho e formação do engenheiro. Belo Horizonte: Fumarc, 2000.

32 CUNHA, F. M. A formação do engenheiro na área humana social: um estudo de caso no curso de engenharia industrial elétrica do Centro Federal de Educação Tecnológica de Minas Gerais. Belo Horizonte: Centro Federal de Educação Tecnológica de Minas Gerais - CEFET-MG -, 1998.

FLEURY, A.; VARGAS, N. (orgs.). Organização do trabalho: um enfoque interdisciplinar. São Paulo: Atlas, 1983.

GRAÇA, L. Legislação sobre a saúde e segurança do trabalho. Lisboa, 22 mar. 2005. Disponível em: <http://www.ensp.unl.pt/lgraca/historial_ legis |80I_|890.html>. Acesso em: 20 fev. 2008.

GORENDER, J.; RAMPINELLI, W. J. O PCB e sua atuação nos anos 50: Waldir José Rampinelli entrevista Jacob Gorender. Revista Brasileira de História. July 2003, v. 23, n. 45, p. 303-309. Disponível em: <http:// www.scielo.br/scielo. php?script $=$ sci_arttext\&pid $=S 0102-$ 0|882003000 I000 |3>. Acesso em: I 3 dez 2007 
INSTITUTO MILITAR DE ENGENHARIA. Da Real Academia Militar de Artilharia, Fortificação e Desenho ao Instituto Militar de Engenharia. 1999. Disponível em: <http://aquarius.ime.eb.br/ sdl/ >. Acesso em: I 5 jul. 2007.

KAWAMURA, L. K. Engenheiro: trabalho e ideologia. 2. ed. São Paulo: Ática, n. 57, I98I (Ensaios)

LAUDARES, J. B. A formação do engenheiro em duas instituições mineiras: o Centro de Educação Tecnológica de Minas Gerais e o Instituto Politécnico da Pontifícia Universidade Católica de Minas Gerais. Belo Horizonte: Centro Federal de Educação Tecnológica de Minas Gerais - CEFET-MG -, 1992.

LAUDARES, J. B.; RIBEIRO, S. Trabalho e formação do engenheiro. Revista Brasileira Estudos Pedagógicos. v. 8I , n. 199, set./dez. 2000. Disponível em: <http://www.rbep.inep.gov.br/index.php/RBEP/article/viewFile/I35/I35>. Acesso em: 18 fev. 2008.

PRADO JUNIOR, C. História econômica do Brasil. 23. ed. São Paulo: Brasiliense, 1980.

REIS FILHO, N. G. Museu de Arte Contemporânea da Universidade de São Paulo/USPMAC. Leituras Cartográficas Históricas. São Paulo, mar 2003. Disponível em: <http://www.macvirtual.usp.br/MAC/templates/exposicoes/ exposicao_leituras_cartograficas/exposicao_leituras_cartograficas_leituras_ cartograficas_historicas.asp >. Acesso em 19 fev. 2008.

SILVA, C. P. A chegada de D. João ao Brasil: a fundação da Academia Real Militar em I8I0. In: . A matemática no Brasil: uma história de seu desenvolvimento. 2.ed. São Paulo: Edgard Blucher, 2002. cap. 3. Disponível em: <http://www.accefyn.org.co/PubliAcad/Clovis/Clovispdf/3.pdf. >. Acesso em: 12 jul. 2007.

TELLES, P. C. da S. História da engenharia no Brasil: séculos XVI e XIX. 2. ed. v. I. Rio de Janeiro: Clavero, 1994. 
. História da engenharia no Brasil: século XX. I. ed. v. 2. Rio de Janeiro: Clavero, 1984.

TORRES, J. R. Dicionário histórico, corográfico, heráldico, biográfico, bibliográfico, numismático e artístico. Porto: Tribuna da História Editores, 2000. Disponível em: <http://www.arqnet.pt/dicionario/francojoao.html>. Acesso em: 19 fev. 2008.

UNIVERSIA. História da instituição. Disponível em: <http://www.universia.pt /conteudos/universidades/

universidades_mapa_distrito_02.jsp?curso_id =9\&distrito_id $=\mathrm{I} I>$ Acesso em: 18 fev. 2008.

VITORINO, A. J. R. A reconversão do capital dos mercadores negreiros, os cartéis e a carestia no Brasil dos anos 1850. E-História. Campinas:

Universidade Estadual de Campinas - UNICAMP -, 22 dez. 2004. Disponível em: <http://www.historiaehistoria.com.br/materia.cfm?tb $=$ professores\&id $=\mid 5>$. Acesso em 25 fev. 2008.

WEISS, H. De colônia a nação. In: ENCICLOPÉDIA Delta de História do Brasil. v. 6. Rio de Janeiro: Delta S/A, 1969a.

. O Brasil Monárquico. In: ENCICLOPÉDIA Delta de História do Brasil. v. 7. Rio de Janeiro: Delta S/A, 1969b. 


\section{The courses of enginnering in Brazil and the productives processes transformations: $X I X$ century until the beginning of the XXI century}

\section{Abstract}

This article deals with the relationship between the transformations in the production processes and the modifications in the Engineering Education in Brazil, at the $X I X, X X$ Centuries and the beginning of the $X X I$ century. $A$ straight relation is suppose between the productives processes transformations and the engineering education modification. A revision bibliographic subsidizes the development of the present article. The first part shows the history about engineering courses in Brazil, his beginning until the XIX century. The second part focuses on the transformations of the engineering courses during the $X X$ Century thru the beginning of the XXI century.

Keywords: engineer education; productive process; history boarding. 